\title{
Flammability limits temperature dependence of pure compounds in air at atmospheric pressure
}

\author{
Andrés Z. Mendiburu a, *, João A. de Carvalho Jr. ${ }^{a}$, Christian R. Coronado ${ }^{\text {, }}$, Justo J. Roberts ${ }^{\text {a }}$ \\ a São Paulo State University - UNESP, Campus of Guaratinguetá - FEG, Av. Ariberto P. da Cunha, 333 - Guaratinguetá, SP, CEP 12510410, Brazil \\ ${ }^{\mathrm{b}}$ Federal University of Itajubá - UNIFEI, Mechanical Engineering Institute - IEM, Av BPS, 1303 - Itajubá, MG, CEP 37500903, Brazil
}

\section{A R T I C L E I N F O}

\section{Article history:}

Received 19 May 2016

Received in revised form

10 November 2016

Accepted 10 December 2016

Available online 22 December 2016

\section{Keywords:}

Combustion

Flammable properties

Semi-empirical method

\begin{abstract}
A B S T R A C T
The objective of the present work is to study the temperature dependence of the flammability limits for pure compounds, and to develop a methodology to determine these limits in air at atmospheric pressure and at different initial temperatures of the mixture.

A method to determine the lower flammability limits in those conditions was developed and compared with other methods available in the literature. The developed method shows an average absolute relative error of $3.25 \%$ and a squared correlation coefficient of 0.9928 . Particularly, in the case of compounds with more than 5 carbon atoms, the method presents better accuracy than other available methods.

Likewise, a method to determine the upper flammability limits was developed and compared with other widely accepted method. In this case, the developed methodology shows an average absolute relative error of $3.60 \%$ and a squared correlation coefficient of 0.9957 , showing better accuracy than the available method.
\end{abstract}

() 2016 Elsevier Ltd. All rights reserved.

\section{Introduction}

A flammable gas forming a mixture with air can be flammable or non-flammable in the presence of an ignition source. In a flammable mixture a flame can propagate through it while in a nonflammable mixture a flame cannot propagate. Given certain conditions of temperature and pressure, the key parameter that defines the flammability condition of a mixture is its composition.

A stoichiometric mixture of a flammable compound and air is always flammable. By slightly increasing the air to flammable gas ratio above the stoichiometric condition, a flammable lean mixture is obtained; this process can be repeated until the mixture becomes non-flammable. At this condition the mixture would be too lean as to sustain flame propagation. The leaner composition of the mixture which can sustain flame propagation is known as the lower flammability limit (LFL) and it is characterized by the mole percentage of the flammable gas in that mixture.

On the other hand, by slightly decreasing the air to flammable gas ratio below the stoichiometric condition, a flammable rich mixture is obtained; this process can be repeated until the mixture

\footnotetext{
* Corresponding author.

E-mail address: andresmendiburu@yahoo.es (A.Z. Mendiburu).
}

becomes non-flammable. At this point the mixture is too rich to sustain flame propagation. The richest composition of the mixture which can sustain flame propagation is known as the upper flammability limit (UFL) and it is also characterized by the mole percentage of the flammable gas in that mixture.

Other parameters that affect the flammability limits are the temperature and pressure conditions at which the process occurs. If one of these parameters is held constant and the other is varied, the values of the LFL and UFL will change.

The importance of determining the flammability limits (FL) of a flammable gas relies on the safety operation of several industrial processes; the knowledge of the FL is used to adopt safety measures. Experimental data on the FL for several compounds is available on the literature, mainly at atmospheric pressure and reference temperature conditions. However, there are a large number of flammable compounds for which experimental data of the FL are not known. Furthermore, the FL depends on the pressure and temperature conditions, in which cases fewer experimental data is available.

In the present work the temperature dependence of the flammability limits is studied considering atmospheric pressure. The aim of the study is to develop an accurate methodology to determine the LFL and UFL in air at atmospheric pressure and at different initial mixture temperatures. There are several methods for the 


\begin{tabular}{|c|c|c|c|}
\hline \multicolumn{2}{|c|}{ Abbreviations } & $T_{U F L, T}$ & Adiabatic flame temperature at the UFL for an initial \\
\hline FL & Flammability limit & $T_{\text {stq.T }}$ & Adiabatic flame temperature at the stoichiometric \\
\hline LFL & Lower flammability limit & & composition for an initial temperature $\mathrm{T}, \mathrm{K}$ \\
\hline UFL & Upper flammability limit & $v_{a r}$ & Number of moles of oxygen at the FL composition, mol \\
\hline ARE & Absolute value of the relative error & $v_{a r}^{s}$ & Number of moles of oxygen at the stoichiometric \\
\hline AARE & Average of the absolute values of the relative errors & & composition, mol \\
\hline Symbols & & $v_{a r}^{U F L}$ & $\begin{array}{l}\text { Number of moles of oxygen at the UFL composition, } \\
\text { mol }\end{array}$ \\
\hline$c_{p}$ & Heat capacity at constant pressure, $\mathrm{kJ} / \mathrm{mol}-\mathrm{K}$ & $x_{C}$ & Number of moles of carbon in the molecule of the \\
\hline $\bar{c}_{p}$ & Average heat capacity at constant pressure, $\mathrm{kJ} / \mathrm{mol}-\mathrm{K}$ & & flammable compound, mol \\
\hline $\bar{h}_{f, i}^{0}$ & Formation enthalpy at standard conditions in molar & $x_{H}$ & $\begin{array}{l}\text { Number of moles of hydrogen in the molecule of the } \\
\text { flammable compound, mol }\end{array}$ \\
\hline$h_{i}$ & $\begin{array}{l}\text { Abse, } \mathrm{kJ} / \mathrm{mol} \\
\text { Absolute enthalpy in molar base, } \mathrm{kJ} / \mathrm{mol}\end{array}$ & $x_{O}$ & $\begin{array}{l}\text { Number of moles of oxygen in the molecule of the } \\
\text { flammable compound, mol }\end{array}$ \\
\hline$\Delta \bar{h}_{i}$ & Specific sensible enthalpy, $\mathrm{kJ} / \mathrm{mol}$ & $\phi$ & Equivalence ratio \\
\hline$H_{C}$ & Heat of combustion, kJ & $\theta_{U F L, T}$ & Ratio $T_{s t q, T} / T_{U F L, T}$ \\
\hline$H_{F L, 0}$ & $\begin{array}{l}\text { Heat released at the flammability limit at the } \\
\text { temperature } T_{0}, \mathrm{~kJ}\end{array}$ & $\theta_{U F L, 0}$ & Ratio $T_{s t q, 0} / T_{U F L, 0}$ \\
\hline$H_{F L, T}$ & Heat released at the flammability limit at the & Subscl & \\
\hline$I$ & $\begin{array}{l}\text { temperature } \mathrm{T}, \mathrm{kJ} \\
\text { Parameter defined in section } 6\end{array}$ & 0 & $\begin{array}{l}\text { Variable taken at a temperature considered as } \\
\text { reference }\end{array}$ \\
\hline$L_{T}$ & $\begin{array}{l}\text { Heat losses in the combustion process for the initial } \\
\text { temperature } \mathrm{T}, \mathrm{kJ}\end{array}$ & ar & Variable related to air \\
\hline$k_{U F L}$ & Slope of a straight line representing $\theta_{U F L, T} / \theta_{U F L, 0}$ & $\begin{array}{l}\text { calc } \\
\exp \end{array}$ & $\begin{array}{l}\text { Calculated value of a variable or parameter } \\
\text { Experimental value of a variable or parameter }\end{array}$ \\
\hline$M_{i}$ & Molecular weight, $\mathrm{g} / \mathrm{mol}$ & $F$ & Variable related to the flammable compound \\
\hline$m$ & Slope of a straight line & $P$ & Products \\
\hline$n_{i}$ & Number of moles of species i, mol & $R$ & Reactants \\
\hline $\mathrm{R}^{2}$ & Squared correlation coefficient & $T$ & Variable taken at some temperature $\mathrm{T}$ \\
\hline$T$ & Temperature, $\mathrm{K}$ or ${ }^{\circ} \mathrm{C}$ & & \\
\hline$T_{0}$ & Temperature considered as reference, $\mathrm{K}$ or ${ }^{\circ} \mathrm{C}$ & & \\
\hline
\end{tabular}

determination of the LFL available in the specialized literature, those with wider application were implemented and compared with the method developed in the present work. On the other hand, fewer methods are available to determine the UFL and only one is widely accepted; this method was implemented and compared with the method developed in the present work. In order to develop and test the methods proposed in the present study, a set of experimental data of the FL at atmospheric pressure and different initial temperature was obtained from the literature.

\section{The behavior of the flammability limits with different initial temperatures}

Consider $n_{F}$ moles of a flammable gas forming a mixture with $n_{\text {ar }}$ moles of air. If the mixture corresponds to one of the FL, such limit would be determined by Eq. (1).

$F L=\frac{n_{F}}{n_{F}+n_{a r}}=\frac{1}{1+\left(n_{a r} / n_{F}\right)}=\frac{1}{1+4.76 v_{a r}}$

Therefore, the number of moles of air per mole of flammable gas $\left(4.76 v_{a r}\right)$, defines the value of the FL. The number of moles of oxygen in the air is given by $v_{a r}$. The values of the FL depend on the pressure and temperature conditions.

When the initial pressure of the mixture is held constant the FL of a flammable gas will vary with the initial mixture temperature. From the experimental data, the following behavior is observed:

i) The lower flammability limit (LFL) decreases with the increase of the initial mixture temperature. That is, the ratio $n_{a r} / n_{F}$ increases in value. ii) The upper flammability limit (UFL) increases with the increase of the initial mixture temperature. In other words, the ratio $n_{a r} / n_{F}$ decreases in value.

iii) The flammability limits vary linearly with the increase of the mixture initial temperature. The slope of the function is negative for the LFL and positive for the UFL. Eq. (2) represents this behavior:

$\frac{F L}{F L_{0}}=1+m\left(T-T_{0}\right)$

\section{The modified Burgess - Wheeler Law}

The energy conservation equation for the combustion process at constant pressure of $1 \mathrm{~mol}$ of flammable gas in air and at an initial temperature $T$ is shown in Eq. (3).

$\bar{h}_{f, F}^{0}+\Delta \bar{h}_{F, T}+n_{a r} \Delta \bar{h}_{a r, T}=\sum_{T} n_{i} \bar{h}_{f, i}^{0}+\sum_{T} n_{i} \Delta \bar{h}_{i}+L_{T}$

Dividing by the total number of moles of the reactants $\left(1+n_{a r}\right)$ and rearranging:

$F L_{T} \cdot \Delta \bar{h}_{F, T}+\left(1-F L_{T}\right) \Delta \bar{h}_{a r, T}+F L_{T} \cdot H_{F L, T}=F L_{T}\left(\sum_{T} n_{i} \Delta \bar{h}_{i}+L_{T}\right)$

where $H_{F L, T}$ is the heat released at the FL, given by Eq. (5), and $L_{T}$ represents the heat losses at the initial temperature. 
$H_{F L, T}=\bar{h}_{f, F}^{0}-\sum_{T} n_{i} \bar{h}_{f, i}^{0}$

It can be observed in Eq. (4) that the sum of the sensible enthalpies of the reactants and the heat liberated in the combustion process is used to increase the sensible enthalpies of the products and overcome the heat losses.

The modified Burgess - Wheeler Law, proposed by Zabetakis et al. [1] for the LFL, can de stated as follows:

"For a flammable gas the sum of the heat liberated at the LFL and the sensible enthalpies of the reactants is a constant". This statement is represented by Eq. (6).

$$
\begin{aligned}
& F L_{T}\left[\left(\Delta \bar{h}_{F, T}-\Delta \bar{h}_{a r, T}\right)+H_{F L, T}\right]+\Delta \bar{h}_{a r, T}=F L_{T}\left(\sum_{T} n_{i} \Delta \bar{h}_{i}+L_{T}\right) \\
& \quad=K
\end{aligned}
$$

The term between brackets on the left hand side of Eq. (6) is dominated by the heat liberated, $H_{F L, T}$. The maximum amount of heat which can be released corresponds to the complete combustion of the flammable gas.

As the mixture initial temperature increases, the heat liberated at the LFL will also increase because there is less fuel which, being at a higher initial temperature, can react more efficiently towards complete combustion.

As the mixture initial temperature increases, the heat released at the UFL will decrease, since there is more fuel in excess and the product distribution contains more species of incomplete combustion.

The flammability limit $F L_{0}$ at some temperature $T_{0}$ is considered as a known variable. The temperature $T_{0}$ can be selected as the reference temperature without losing generality. In consequence, the enthalpies of formation are determined at $T_{0}$. Therefore, Eq. (6) becomes:

$F L_{0} H_{F L, 0}=F L_{0}\left(\sum_{T_{0}} n_{i} \Delta \bar{h}_{i}+L_{T_{0}}\right)=K$

For simplicity in the formulation, the sensible enthalpies will be represented by using the average heat capacities at constant pressure, as shown in Eqs. (8) And (9). Also the temperature difference is expressed as $\Delta T=T-T_{0}$.

$\bar{c}_{p, a r, T}=\frac{1}{T-T_{0}} \int_{T_{0}}^{T} c_{p, a r} \mathrm{~d} T$

$\bar{c}_{p, R, T}=\frac{1}{T-T_{0}} \int_{T_{0}}^{T}\left(c_{p, F}-c_{p, a r}\right) \mathrm{d} T$

Dividing the left hand side of Eq. (6) by that of Eq. (7), using Eqs. (8) and (9), and rearranging, the expression shown in Eq. (10) is obtained.

$\frac{F L_{T}}{F L_{0}}=\frac{H_{F L, 0}}{H_{F L, T}+\bar{c}_{p, R, T} \Delta T}\left(1-\frac{\bar{c}_{p, a r, T}}{F L_{0} H_{F L, 0}} \Delta T\right)=1+m \Delta T$

Solving Eq. (10) to find the slope yields Eq. (11).

$$
m=\frac{H_{F L, 0}}{H_{F L, T}+\bar{c}_{p, R, T} \Delta T}\left(\frac{1}{\Delta T}-\frac{1}{\Delta T} \frac{H_{F L, T}+\bar{c}_{p, R, T} \Delta T}{H_{F L, 0}}-\frac{\bar{c}_{p, a r, T}}{F L_{0} H_{F L, 0}}\right)
$$

Therefore, for the determination of $m$, it would be necessary to know the heat liberated at different initial temperatures of the flammable mixture. Some assumptions must be made in order to express Eq. (11) in simpler terms:

- The heat liberated at the LFL is constant at different initial temperatures of the mixture. Furthermore, it is equal to the heat of combustion as shown below:

$H_{C}=\bar{h}_{f, F}^{0}-x_{C} \bar{h}_{f, \mathrm{CO}_{2}}^{0}-\frac{x_{H}}{2} \bar{h}_{f, H_{2} \mathrm{O}}^{0}$

- The average heat capacities at constant pressure of the reactants can be represented by the heat capacity of air. Therefore, $\bar{c}_{p, R, T}=0$.

- The slope of the function at the UFL and at the LFL presents the same value, but with different sign.

Considering these assumptions in Eq. (11) and replacing the results in Eq. (10):

$\frac{L F L_{T}}{L F L_{0}}=1-\frac{\bar{c}_{p, a r, T}}{F L_{0} H_{C}}\left(T-T_{0}\right)$

$\frac{U F L_{T}}{U F L_{0}}=1+\frac{\bar{c}_{p, a r, T}}{F L_{0} H_{C}}\left(T-T_{0}\right)$

According to Zabetakis [2], the slope of Eqs. (13) and (14) can be obtained by considering that the heat capacity at constant pressure of air is constant and equal to $0.0075 \mathrm{kcal} / \mathrm{mol}-\mathrm{K}$, and that the product $L F L_{0} H_{C}$ is constant and equal to $10.4 \mathrm{kcal} / \mathrm{mol}$, then:

$\frac{L F L_{T}}{L F L_{0}}=1-0.000721\left(T-T_{0}\right)$

$\frac{U F L_{T}}{U F L_{0}}=1+0.000721\left(T-T_{0}\right)$

In the present work, Zabetakis' equations will be validated with experimental data and compared with two developed methods.

\section{Methods to determine the FL at different initial temperatures}

Most of the methods available in the literature were developed to determine the LFLs, such as the works of Catoire and Nauder [3], Rowley et al. [4], Britton [5], Britton and Frurip [6], Mendiburu et al. [7], Zlochower [8], Mendiburu et al. [9] and Liaw and Chen [10]. Fewer studies are devoted to determine the UFLs at different initial temperatures, among them the works of Mendiburu et al. [11] and Liaw and Chen [10].

Some of these works ([7] [8], and [10]), are based on the assumption that the adiabatic flame temperature at the LFL is constant with respect to the initial mixture temperature. Such consideration gives good results for the case of hydrocarbons; however, the theoretical results deviate from the experimental data for $\mathrm{CHO}$ compounds. The method developed by Liaw and Chen [10] was applied to predict both FL by considering heat losses in the processes. The authors [10] concluded that the differences in the LFLs prediction were negligible with respect to the heat losses; also, 
the predicted UFLs based on adiabatic conditions were more accurate than those predicted by considering heat losses.

Some of the above cited works $[2-4,6]$ are considered for comparison with the results obtained by using Eqs. (15) and (16) and with the methods developed in the present study.

\section{Empirical equations for FLs at different initial temperatures}

There are several studies which have developed empirical equations to represent experimental data. A list of such works is presented in Table 1, along with other relevant information.

The slope of Eq. (2) can be determined for each compound of the experimental data set compiled for the development of the present work. The slopes determined by directly adjusting the straight lines to the experimental data are represented by $m_{L F L, \exp }$ and $m_{U F L, \exp }$, for the LFL and UFL, respectively. The resulting values for $m_{L F L \text {,exp }}$ and $m_{U F L, \text { exp }}$ are presented in Tables 2 and 3, respectively. Other parameters are also shown in Tables 2 and 3, these will be introduced later.

The use of the experimentally determined slopes allows the estimation of the FL at different initial temperatures for the compounds presented in Tables 2 and 3

\section{Method for estimating the LFL at different initial temperatures}

The method for the determination of the LFL's at different mixture initial temperatures is based on a procedure that adjusts a correlation function to approximate the value of the slope determined with the experimental data. Therefore, a calculated slope for the LFLs is obtained, $m_{L F L \text {,calc }}$.

In the method proposed by Zabetakis [2], there are no means to differentiate among flammable gases because the slope is the same for all compounds. In order to differentiate among flammable gases the parameter $I$ is introduced.

In the works of Kondo et al. [17] and Rowley et al. [28], a spherical vessel of $12 \mathrm{~L}$ volume was used in the experiments. Assuming that the mixture behaves as an ideal gas, at atmospheric pressure, with a $12 \mathrm{~L}$ volume, and knowing the initial temperature, the number of moles of the mixture can be determined $\left(n_{T}\right)$. The value of $n_{T}$ will change with the initial temperature; however, for the determination of parameter $I$, the value of $n_{T}$ corresponds to the initial mixture temperature $T_{0}$. Also, since at the initial temperature $T_{0}$, the lower flammability limit $L F L_{0}$ is known, the number of moles of the flammable gas $\left(n_{F}\right)$ can be easily determined. Taking into account these considerations, the value of the parameter $I$ can be determined by Eq. (17).

$I=\frac{M_{F}}{n_{F} H_{C}}$

The parameter $I$ is the combination of the molecular weight of the flammable gas $\left(M_{F}\right)$, its heat of combustion $\left(H_{C}\right)$, given by Eq. (12), and the number of moles of the flammable gas $\left(n_{F}\right)$, when the mixture is at $T_{0}$, atmospheric pressure and occupies a volume of $12 \mathrm{~L}$.

By applying a multiple linear regression, the following correlation was obtained for the calculated slope:

$m_{L F L, \text { calc }}=\frac{8.3959}{10^{4}}+\frac{9.6643}{10^{5}} I+\frac{2.6402}{10^{6}} I^{2}+\frac{8.3413}{10^{10}} H_{C} \cdot I$

The values of the parameters $I, H_{C}$ and $m_{L F L, \text { calc }}$ for the studied compounds are presented in the last three columns of Table 2 . The validation of the proposed method is presented in Section 8 of Results and Discussions.

\section{Method for estimating the UFL at different initial temperatures}

The method to determine the UFL's at different initial temperatures of the mixture is based on the calculated adiabatic flame temperature. Additionally, some considerations are assumed to determine this temperature:

i) A fraction of the flammable gas undergoes complete combustion,

ii) The unreacted flammable gas is treated as an inert and its sensible enthalpy is represented by the sensible enthalpy of an equal mass of air,

iii) The sensible enthalpies of the flammable gases are determined by considering average heat capacities at constant pressure.

The global combustion reaction is, then, given by Eq. (19).

$$
\begin{aligned}
& C_{x_{C}} H_{x_{H}} O_{x_{O}}+v_{a r}^{U F L}\left(O_{2}+3,76 N_{2}\right) \rightarrow \phi^{-1}\left(x_{C} C_{2}+\frac{x_{H}}{2} H_{2} O\right) \\
& +3,76 v_{a r}^{U F L} N_{2}+\left(1-\phi^{-1}\right) C_{x_{C}} H_{x_{H}} O_{x_{O}}
\end{aligned}
$$

where $v_{a r}^{U F L}$ is the number of moles of oxygen at the UFL composition and $\phi$ is the equivalence ratio given by Eq. (20).

Table 1

\begin{tabular}{|c|c|c|c|c|}
\hline Reference & Studied compounds & Flammability limits & Temperature range $\left({ }^{\circ} \mathrm{C}\right)$ & Pressure range $(\mathrm{kPa})$ \\
\hline Goethals et al. [12] & Toluene & LFL, UFL & $60-225$ & $100-500$ \\
\hline Liu and Zhang [13] & Hydrogen & LFL, UFL & $21-90$ & $100-400$ \\
\hline Vanderstraeten et al. [14] & Methane & UFL & $20-200$ & $100-5500$ \\
\hline \multirow[t]{5}{*}{ Van den Schoor [15] } & Ethane & UFL & $20-250$ & $100-3000$ \\
\hline & Propane & UFL & $20-250$ & $100-1000$ \\
\hline & n-Butane & UFL & $20-250$ & $100-300$ \\
\hline & Ethylene & UFL & $20-260^{\mathrm{a}}$ & $100-3000$ \\
\hline & Propylene & UFL & $20-250^{\mathrm{b}}$ & $100-1000$ \\
\hline \multirow[t]{4}{*}{ Hustad and Sonju [16] } & Methane & LFL & $25-450$ & 101.325 \\
\hline & Commercial Butane & LFL & $25-450$ & 101.325 \\
\hline & Hydrogen & LFL & $25-450$ & 101.325 \\
\hline & Carbon Monoxide & LFL & $25-450$ & 101.325 \\
\hline
\end{tabular}

Works which present experimental data accompanied by empirical correlations.

\footnotetext{
a The temperature range was 20-230 from 1500 to $2500 \mathrm{kPa}$ and it was 20-200 for $3000 \mathrm{kPa}$.
}

b The temperature range was $20-200$ for $1000 \mathrm{kPa}$. 
Table 2

Values of parameters for the determination of the LFL at different initial temperatures of the mixture.

\begin{tabular}{|c|c|c|c|c|c|c|c|}
\hline References & Compounds & Formula & CAS\# & $m_{L F L, \exp }\left(1 /{ }^{\circ} C\right)$ & $H_{C}(k J)$ & $I(\mathrm{~g} / \mathrm{mol} . \mathrm{kJ})$ & $m_{L F L, \text { calc }}\left(1 /{ }^{\circ} \mathrm{C}\right)$ \\
\hline Kondo et al. [17] & Dimethyl ether & $\mathrm{C}_{2} \mathrm{H}_{6} \mathrm{O}$ & $115-10-6$ & 0.000957 & 1328.42 & 2.0745 & 0.001054 \\
\hline Kondo et al. [17] & Methyl formate & $\mathrm{C}_{2} \mathrm{H}_{4} \mathrm{O}_{2}$ & $107-31-3$ & 0.000825 & 933.80 & 2.4318 & 0.001092 \\
\hline Kondo et al. [17] & Methane & $\mathrm{CH}_{4}$ & $74-82-8$ & 0.000658 & 802.30 & 0.8121 & 0.000920 \\
\hline Wierzba and Wang [18] & Methane & $\mathrm{CH}_{4}$ & $74-82-8$ & 0.000850 & 802.30 & 0.8315 & 0.000922 \\
\hline Li et al. [19] & Methane & $\mathrm{CH}_{4}$ & $74-82-8$ & 0.000609 & 802.30 & 0.8200 & 0.000921 \\
\hline White [20] & Methane & $\mathrm{CH}_{4}$ & $74-82-8$ & 0.000658 & 802.30 & 0.6359 & 0.000903 \\
\hline Kondo et al. [17] & Propane & $\mathrm{C}_{3} \mathrm{H}_{8}$ & $74-98-6$ & 0.000810 & 2043.17 & 2.1098 & 0.001059 \\
\hline Kondo et al. [17] & iso-Butane & $\mathrm{C}_{4} \mathrm{H}_{10}$ & $75-28-5$ & 0.000915 & 2649.02 & 2.6170 & 0.001116 \\
\hline Kondo et al. [17] & Propylene & $\mathrm{C}_{3} \mathrm{H}_{6}$ & $115-07-1$ & 0.000915 & 1926.45 & 2.0078 & 0.001048 \\
\hline Kondo et al. [17] & Ethylene & $\mathrm{C}_{2} \mathrm{H}_{4}$ & $74-85-1$ & 0.000823 & 1323.17 & 1.5453 & 0.000997 \\
\hline Craven and Foster [21] & Ethylene & $\mathrm{C}_{2} \mathrm{H}_{4}$ & $74-85-1$ & 0.000836 & 1323.17 & 1.6344 & 0.001006 \\
\hline White [20] & Ethylene & $\mathrm{C}_{2} \mathrm{H}_{4}$ & $74-85-1$ & 0.000745 & 1323.17 & 1.2317 & 0.000964 \\
\hline White [20] & Acetylene & $\mathrm{C}_{2} \mathrm{H}_{2}$ & $74-86-2$ & 0.000913 & 1255.60 & 1.4325 & 0.000985 \\
\hline Kondo et al. [17] & Carbon Monoxide & $\mathrm{CO}$ & $630-08-0$ & 0.000791 & 282.99 & 1.6125 & 0.001003 \\
\hline Wierzba and Wang [18] & Carbon Monoxide & $\mathrm{CO}$ & $630-08-0$ & 0.000882 & 282.99 & 1.4832 & 0.000989 \\
\hline Karim et al. [22] & Carbon Monoxide & $\mathrm{CO}$ & $630-08-0$ & 0.000801 & 282.99 & 1.4663 & 0.000987 \\
\hline White et al. [20] & Carbon Monoxide & $\mathrm{CO}$ & $630-08-0$ & 0.000844 & 282.99 & 1.2168 & 0.000961 \\
\hline Kondo et al. [17] & Ammonia & $\mathrm{NH}_{3}$ & $7664-41-7$ & 0.000575 & 316.80 & 0.6950 & 0.000908 \\
\hline White [23] (downward) & Ammonia & $\mathrm{NH}_{3}$ & $7664-41-7$ & 0.000970 & 316.80 & 0.5706 & 0.000896 \\
\hline White [23] (horizontal) & Ammonia & $\mathrm{NH}_{3}$ & $7664-41-7$ & 0.000582 & 316.80 & 0.5878 & 0.000897 \\
\hline White [23] (upward) & Ammonia & $\mathrm{NH}_{3}$ & $7664-41-7$ & 0.000559 & 316.80 & 0.6645 & 0.000905 \\
\hline Ciccarelli et al. [24] & Ammonia & $\mathrm{NH}_{3}$ & $7664-41-7$ & 0.000861 & 316.80 & 0.6528 & 0.000904 \\
\hline Chang et al. [25] & Methanol & $\mathrm{CH}_{4} \mathrm{O}$ & $67-56-1$ & 0.001500 & 672.17 & 2.2808 & 0.001075 \\
\hline Coronado et al. [26] & Ethanol & $\mathrm{C}_{2} \mathrm{H}_{6} \mathrm{O}$ & $64-17-5$ & 0.001213 & 1278.52 & 1.9264 & 0.001038 \\
\hline Goethals [12] & Toluene & $\mathrm{C}_{7} \mathrm{H}_{8}$ & $108-88-3$ & 0.001327 & 3772.06 & 4.7745 & 0.001376 \\
\hline White et al. [20] & n-Pentane & $\mathrm{C}_{5} \mathrm{H}_{12}$ & $109-66-0$ & 0.000696 & 3271.77 & 2.8878 & 0.001149 \\
\hline Chang et al. [25] & Benzene & $\mathrm{C}_{6} \mathrm{H}_{6}$ & $71-43-2$ & 0.000909 & 3169.51 & 5.7145 & 0.001493 \\
\hline Wierzba and Wang [18] & Hydrogen & $\mathrm{H}_{2}$ & $1333-74-0$ & 0.001460 & 241.83 & 0.4343 & 0.000882 \\
\hline Ciccarelli et al. [24] & Hydrogen & $\mathrm{H}_{2}$ & $1333-74-0$ & 0.000848 & 241.83 & 0.3701 & 0.000876 \\
\hline Karim et al. [22] & Hydrogen & $\mathrm{H}_{2}$ & $1333-74-0$ & 0.003358 & 241.83 & 0.4100 & 0.000880 \\
\hline White et al. [20] & Hydrogen & $\mathrm{H}_{2}$ & 1333-74-0 & 0.000872 & 241.83 & 0.1772 & 0.000857 \\
\hline Wierzba et al. [27] & Hydrogen & $\mathrm{H}_{2}$ & $1333-74-0$ & 0.001034 & 241.83 & 0.3454 & 0.000873 \\
\hline Rowley et al. [28] & Methanol & $\mathrm{CH}_{4} \mathrm{O}$ & $67-56-1$ & 0.001149 & 672.17 & 1.3951 & 0.000980 \\
\hline Rowley et al. [28] & 1-hexine & $\mathrm{C}_{6} \mathrm{H}_{10}$ & $693-02-7$ & 0.001603 & 3692.56 & 5.2554 & 0.001437 \\
\hline Rowley et al. [28] & Butanol & $\mathrm{C}_{4} \mathrm{H}_{10} \mathrm{O}$ & $71-36-3$ & 0.001310 & 2506.22 & 3.9705 & 0.001273 \\
\hline Rowley et al. [28] & Methyl benzoate & $\mathrm{C}_{8} \mathrm{H}_{8} \mathrm{O}_{2}$ & $93-58-3$ & 0.002212 & 3846.18 & 8.7010 & 0.001908 \\
\hline Rowley et al. [28] & 1-Octanol & $\mathrm{C}_{8} \mathrm{H}_{18} \mathrm{O}$ & $111-87-5$ & 0.001820 & 4968.61 & 8.1929 & 0.001843 \\
\hline Rowley et al. [28] & Phenetole & $\mathrm{C}_{8} \mathrm{H}_{10} \mathrm{O}$ & $103-73-1$ & 0.002015 & 4255.71 & 7.3406 & 0.001717 \\
\hline Rowley et al. [28] & 4-Methyl-2-pentanol & $\mathrm{C}_{6} \mathrm{H}_{14} \mathrm{O}$ & $108-11-2$ & 0.001584 & 3709.81 & 5.7482 & 0.001500 \\
\hline Rowley et al. [28] & Dibutyl amine & $\mathrm{C}_{8} \mathrm{H}_{19} \mathrm{~N}$ & $111-92-2$ & 0.002210 & 3882.81 & 9.6620 & 0.002051 \\
\hline Rowley et al. [28] & 2-penteno & $\mathrm{C}_{10} \mathrm{H}_{16}$ & $80-56-8$ & 0.001979 & 5853.43 & 8.2118 & 0.001851 \\
\hline Rowley et al. [28] & 2-methyl-1,3-propanediol & $\mathrm{C}_{4} \mathrm{H}_{10} \mathrm{O}_{2}$ & $2163-42-0$ & 0.001750 & 2277.32 & 6.9605 & 0.001653 \\
\hline Rowley et al. [28] & Hexyl Formate & $\mathrm{C}_{7} \mathrm{H}_{14} \mathrm{O}_{2}$ & $629-33-4$ & 0.001763 & 3928.95 & 7.7408 & 0.001771 \\
\hline Rowley et al. [28] & Octyl formate & $\mathrm{C}_{9} \mathrm{H}_{18} \mathrm{O}_{2}$ & $112-32-3$ & 0.002056 & 5151.68 & 10.1597 & 0.002138 \\
\hline Rowley et al. [28] & Di iso butyl phthalate & $\mathrm{C}_{16} \mathrm{H}_{22} \mathrm{O}_{4}$ & $84-69-5$ & 0.004312 & 7869.14 & 22.0334 & 0.004395 \\
\hline Rowley et al. [28] & Ethyl Lactate & $\mathrm{C}_{5} \mathrm{H}_{10} \mathrm{O}_{3}$ & $97-64-3$ & 0.001754 & 2481.66 & 6.9838 & 0.001658 \\
\hline
\end{tabular}

$\phi=\frac{v_{a r}^{S}}{v_{a r}^{U F L}}$

The number of moles of oxygen at the stoichiometric composition $\left(v_{\text {ar }}^{s}\right)$ is determined as follows:

$v_{a r}^{s}=x_{C}+\frac{x_{H}}{4}-\frac{x_{O}}{2}$

Since the mass of air is equal to that of the unreacted flammable gas, the equivalent number of moles of air is determined using the following relation:

$n_{a r}^{e q}=\left(1-\phi^{-1}\right) \frac{M_{F}}{M_{a r}}$
The molecular weight of air $\left(M_{a r}\right)$ was considered as $28.96 \mathrm{~g}$ mol. The energy conservation law is given by Eq. (23).

$$
\begin{aligned}
\phi^{-1} h_{F}+\left[v_{a r}^{U F L}+\left(1-\phi^{-1}\right) M_{m}\right] h_{a r, R} \\
\quad=\phi^{-1}\left(x_{C} h_{\mathrm{CO}_{2}}+\frac{x_{H}}{2} h_{\mathrm{H}_{2} \mathrm{O}}\right)+3,76 v_{a r}^{U F L} h_{N_{2}}+\left(1-\phi^{-1}\right) M_{m} h_{a r, P}
\end{aligned}
$$

where $M_{m}$ represents the ratio $M_{m}=M_{F} / M_{a r}$, the subscripts R and $P$ refer to reactants and products, respectively. Isolating the number of moles of oxygen at the UFL Eq. (24) is obtained.

$v_{a r}^{U F L}=\frac{v_{a r}^{S} M_{m}\left(h_{a r, P}-h_{a r, R}\right)}{h_{F}-x_{C} h_{C O_{2}}-\frac{\chi_{H}}{2} h_{H_{2} O}+M_{m}\left(h_{a r, P}-h_{a r, R}\right)+v_{a r}^{S}\left(h_{a r, R}-3,76 h_{N_{2}}\right)}$ 
Table 3

Values of parameters for the determination of the UFL at different initial temperatures of the mixture.

\begin{tabular}{|c|c|c|c|c|c|}
\hline References & Composto & Fórmula & $m_{U F L, \exp }\left(1 /{ }^{\circ} \mathrm{C}\right)$ & $\bar{h}_{f, F}^{0}(\mathrm{~kJ} / \mathrm{mol})$ & $I(\mathrm{~g} / \mathrm{mol} . \mathrm{kJ})$ \\
\hline Kondo et al. [17] & Methane & $\mathrm{CH}_{4}$ & 0.000633 & -74.9 & 0.2560 \\
\hline Wierzba and Wang [18] & Methane & $\mathrm{CH}_{4}$ & 0.000719 & -74.9 & 0.2910 \\
\hline Li et al. [19] & Methane & $\mathrm{CH}_{4}$ & 0.000532 & -74.9 & 0.2611 \\
\hline Van Den Schoor [15] & Methane & $\mathrm{CH}_{4}$ & 0.000941 & -74.9 & 0.2504 \\
\hline Vanderstraeten et al. [14] & Methane & $\mathrm{CH}_{4}$ & 0.000854 & -74.9 & 0.2552 \\
\hline White [20] & Methane & $\mathrm{CH}_{4}$ & 0.000740 & -74.9 & 0.3106 \\
\hline Kondo et al. [17] & Propane & $\mathrm{C}_{3} \mathrm{H}_{8}$ & 0.000314 & -104.7 & 0.4413 \\
\hline Van Den Schoor [15] & Propane & $\mathrm{C}_{3} \mathrm{H}_{8}$ & 0.001470 & -104.7 & 0.4240 \\
\hline Kondo et al. [17] & iso-Butane & $\mathrm{C}_{4} \mathrm{H}_{10}$ & $0.000025^{\mathrm{a}}$ & -134.2 & 0.5565 \\
\hline Kondo et al. [17] & Propylene & $\mathrm{C}_{3} \mathrm{H}_{6}$ & 0.000469 & 20.4 & 0.4250 \\
\hline Van Den Schoor [15] & Propylene & $\mathrm{C}_{3} \mathrm{H}_{6}$ & 0.001413 & 20.4 & 0.3502 \\
\hline Kondo et al. [17] & Ethylene & $\mathrm{C}_{2} \mathrm{H}_{4}$ & 0.001284 & 52.5 & 0.1393 \\
\hline White [20] & Ethylene & $\mathrm{C}_{2} \mathrm{H}_{4}$ & 0.000808 & 52.5 & 0.3102 \\
\hline Van Den Schoor [15] & Ethylene & $\mathrm{C}_{2} \mathrm{H}_{4}$ & 0.001522 & 52.5 & 0.1218 \\
\hline Kondo et al. [17] & Ammonia & $\mathrm{NH}_{3}$ & 0.000695 & -45.9 & 0.3645 \\
\hline Ciccarelli et al. [24] & Ammonia & $\mathrm{NH}_{3}$ & 0.000770 & -45.9 & 0.3714 \\
\hline White [23] (downward) & Ammonia & $\mathrm{NH}_{3}$ & 0.001038 & -45.9 & 0.5412 \\
\hline White [23] (horizontal) & Ammonia & $\mathrm{NH}_{3}$ & 0.000680 & -45.9 & 0.4196 \\
\hline White [23] (upward) & Ammonia & $\mathrm{NH}_{3}$ & 0.00633 & -45.9 & 0.4022 \\
\hline Goethals [12] & Toluene & $\mathrm{C}_{7} \mathrm{H}_{8}$ & 0.000506 & 50.1 & 0.6829 \\
\hline Wierzba and Wang [18] & Hydrogen & $\mathrm{H}_{2}$ & 0.000397 & 0.0 & 0.0227 \\
\hline Ciccarelli et al. [24] & Hydrogen & $\mathrm{H}_{2}$ & 0.000379 & 0.0 & 0.0222 \\
\hline White [20] & Hydrogen & $\mathrm{H}_{2}$ & 0.000367 & 0.0 & 0.0233 \\
\hline Wierzba et al. [27] & Hydrogen & $\mathrm{H}_{2}$ & 0.000339 & 0.0 & 0.0213 \\
\hline Chang et al. [25] & Benzene & $\mathrm{C}_{6} \mathrm{H}_{6}$ & 0.001667 & 82.9 & 1.0477 \\
\hline Van Den Schoor [15] & Ethane & $\mathrm{C}_{2} \mathrm{H}_{6}$ & 0.000694 & -84.0 & 0.2556 \\
\hline Van Den Schoor [15] & n-Butane & $\mathrm{C}_{4} \mathrm{H}_{10}$ & 0.001165 & -125.6 & 0.4613 \\
\hline White [20] & n-pentane & $\mathrm{C}_{5} \mathrm{H}_{12}$ & 0.000678 & -146.8 & 0.9819 \\
\hline White [20] & Acetylene & $\mathrm{C}_{2} \mathrm{H}_{2}$ & 0.002551 & 226.7 & 0.0755 \\
\hline Kondo et al. [17] & Dimethyl ether & $\mathrm{C}_{2} \mathrm{H}_{6} \mathrm{O}$ & 0.002928 & -184.1 & 0.2758 \\
\hline Kondo et al. [17] & Methyl formate & $\mathrm{C}_{2} \mathrm{H}_{4} \mathrm{O}_{2}$ & 0.000928 & -336.9 & 0.5754 \\
\hline Chang et al. [25] & Methanol & $\mathrm{CH}_{4} \mathrm{O}$ & 0.002584 & -205.0 & 0.3142 \\
\hline Coronado et al. [26] & Ethanol & $\mathrm{C}_{2} \mathrm{H}_{6} \mathrm{O}$ & 0.004661 & -234.0 & 0.4139 \\
\hline Kondo et al. [17] & Carbon Monoxide & $\mathrm{CO}$ & 0.000390 & -110.5 & 0.2728 \\
\hline Wierzba and Wang [18] & Carbon Monoxide & $\mathrm{CO}$ & 0.000569 & -110.5 & 0.3033 \\
\hline White [20] & Carbon Monoxide & $\mathrm{CO}$ & 0.000268 & -110.5 & 0.2833 \\
\hline
\end{tabular}

a The UFL variation for this compound was small.

The adiabatic flame temperature for the UFL at any initial temperature $T$ was determined by solving Eq. (23); this temperature is denoted by $T_{U F L, T}$. Also, the adiabatic flame temperature at the stoichiometric composition and at any initial temperature $T$ was determined and denoted by $T_{\text {stq,T }}$.

The value of the upper flammability limit at $T_{0}$ was used to determine the adiabatic flame temperature denoted by $T_{U F L, 0}$, the adiabatic flame temperature at the stoichiometric composition and at $T_{0}$ was determined and is denoted by $T_{s t q, 0}$.

The ratio of the adiabatic flame temperature at the stoichiometric composition to that at the UFL composition is represented by $\theta_{U F L, T}$. At the initial temperature $T_{0}$ the value of this ratio is denoted by $\theta_{U F L, 0}$. The following equation shows that the quotient $\theta_{U F L, T} / \theta_{U F L, 0}$ increases its value linearly as the initial temperature difference increases.

$\frac{\theta_{U F L, T}}{\theta_{U F L, 0}}=\frac{T_{s t q, T} / T_{U F L, T}}{T_{s t q, 0} / T_{U F L, 0}}=1+k_{U F L}\left(T_{T}-T_{0}\right)$

In order to approximate the value of $T_{U F L, T}$, it is necessary to determine the factor $k_{U F L}$. In the method here proposed, this is done by means of a correlation. Once the value of the adiabatic flame temperature has been approximated, the number of moles of oxygen can be determined using Eq. (24). In the present work, a total of 18 flammable compounds were studied, obtaining two correlation functions:

For $\mathrm{C}-\mathrm{H}$ compounds, hydrogen and ammonia.
$k_{U F L}=\frac{3.7611}{10^{4}}-\frac{3.0500}{10^{4}} I+\frac{2.5988}{10^{6}} \bar{h}_{f, F}^{0}+\frac{2.0798}{10^{8}}\left(\bar{h}_{f, F}^{0}\right)^{2}$

For $\mathrm{C}-\mathrm{H}-\mathrm{O}$ compounds and carbon monoxide

$k_{U F L}=-\frac{5.8362}{10^{-3}}-\frac{3.8838}{10^{4}} I-\frac{6.7817}{10^{5}} \bar{h}_{f, F}^{0}-\frac{1.4430}{10^{7}}\left(\bar{h}_{f, F}^{0}\right)^{2}$

The value of the parameter $I$ is calculated with Eq. (17), and the number of moles of the flammable gas is determined by considering $U F L_{0}$. The other parameter used was the enthalpy of formation of the flammable gas $\left(\bar{h}_{f, F}^{0}\right)$. Once the ratio $\theta_{U F L, T} / \theta_{U F L, 0}$ has been approximated, Eq. (28) is employed to determine the desired adiabatic flame temperature:

$T_{U F L, T}=\frac{T_{\text {Stq,T }}}{\theta_{U F L, 0}}\left(\frac{\theta_{U F L, T}}{\theta_{U F L, 0}}\right)^{-1}$

To perform the calculations, the flammable compounds' heat capacities at constant pressure were obtained from the NIST Chemistry Web Book [29]. The data were then adjusted to two degree polynomials as a function of temperature ranging from 100 to $1500 \mathrm{~K}$. An analogous expression to that shown in Eq. (8) was used setting the integration interval from $T_{0}$ to $T$. The other species' absolute enthalpies were determined by using the NASA-Glenn coefficients given by McBride et al. [30]. The values of the necessary parameters are presented in Table 3. 
Table 4

Results and comparison of the method for determining the LFL at different initial temperatures of the mixture.

\begin{tabular}{llll}
\hline Method & $\mathrm{N}$ & AARE (\%) & $\mathrm{R}^{2}$ \\
\hline Britton and Frurip [6] & 161 & 4.44 & 0.9946 \\
Catoire and Naudet [3] & 140 & 14.64 & 0.9003 \\
Rowley et al. [4] & 109 & 5.95 & 0.9857 \\
Zabetakis [2] & 180 & 4.82 & 0.9948 \\
This work & 180 & 3.25 & 0.9928 \\
\hline
\end{tabular}

Table 5

Further comparison of the method for the LFL at different initial temperatures.

\begin{tabular}{|c|c|c|c|c|c|c|c|}
\hline \multirow[t]{2}{*}{ Set } & \multirow[t]{2}{*}{$\mathrm{N}$} & \multicolumn{2}{|c|}{ Zabetakis [2] } & \multicolumn{2}{|c|}{$\begin{array}{l}\text { Britton and Frurip } \\
{[6]}\end{array}$} & \multicolumn{2}{|l|}{ This work } \\
\hline & & AARE (\%) & $\mathrm{R}^{2}$ & AARE (\%) & $\mathrm{R}^{2}$ & AARE (\%) & $\mathrm{R}^{2}$ \\
\hline$x_{C} \leq 5$ & 110 & 2.36 & 0.9978 & 2.75 & 0.9955 & 2.73 & 0.9972 \\
\hline$x_{C}>5$ & 30 & 11.74 & 0.6844 & 10.33 & 0.7553 & 2.01 & 0.9851 \\
\hline $\mathrm{NH}_{3}$ & 21 & 4.70 & 0.8593 & 4.88 & 0.8499 & 5.76 & 0.7649 \\
\hline $\mathrm{H}_{2}$ & 19 & 8.28 & 0.9439 & - & - & 5.47 & 0.9639 \\
\hline
\end{tabular}
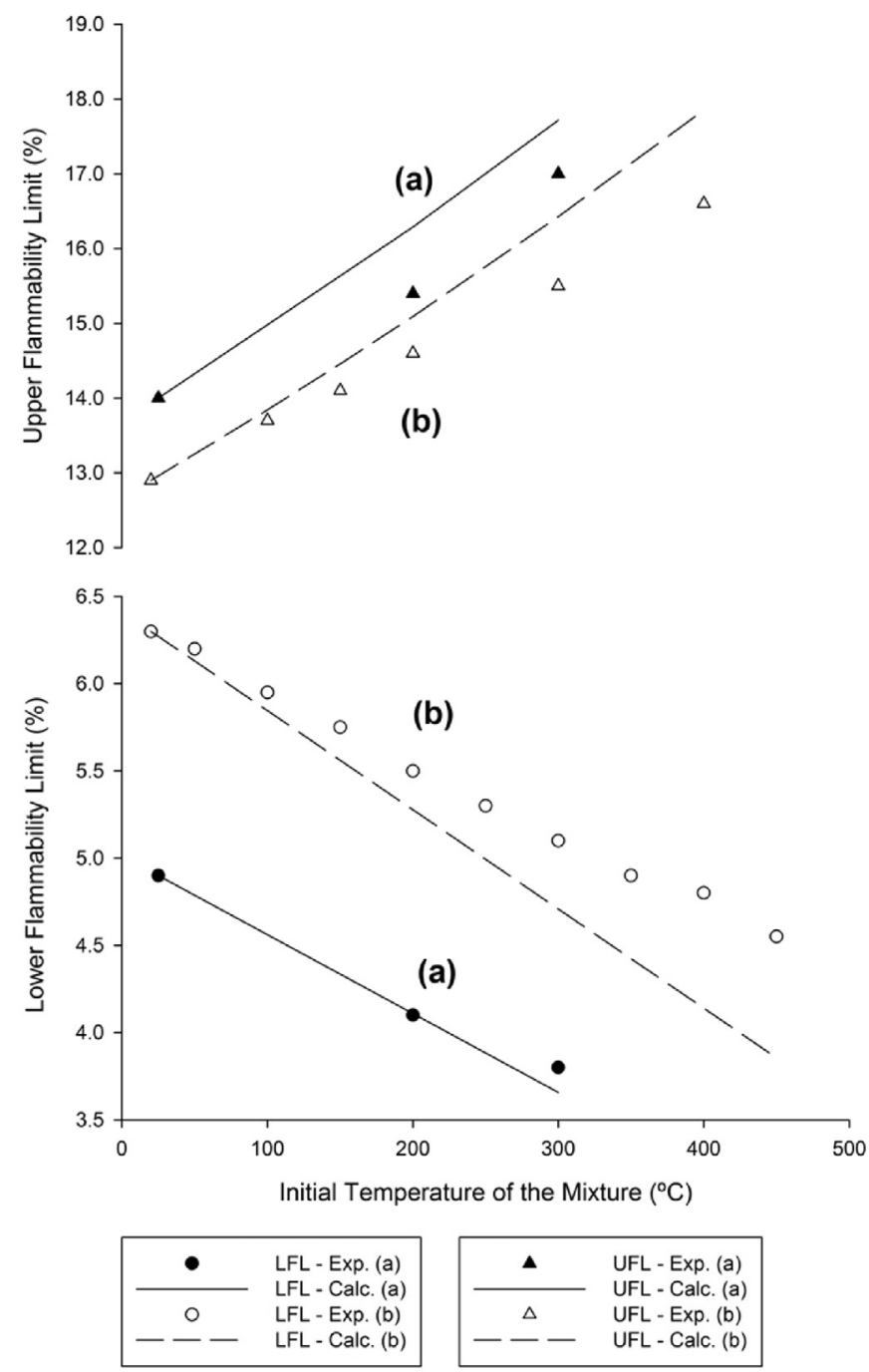

Fig. 1. Calculated and experimental flammability limits of methane $\left(\mathrm{CH}_{4}\right)$ at different initial temperatures of the mixture and atmospheric pressure. Experimental data by: (a) Wierzba and Wang [18] and (b) White [20].

\section{Results and discussions}

The method proposed in the present study was implemented along with the methods available in the literature. The results are compared in terms of the absolute relative error (ARE), for an individual flammable gas; in terms of the average absolute relative error (AARE), for a set of flammable gases; and in terms of the squared correlation coefficient $\left(\mathrm{R}^{2}\right)$, also for a set of flammable gases. The subscripts "exp" and "calc" refer to experimental and calculated data, respectively.

The absolute relative error, ARE, is determined using Eq. (29). The average absolute relative error, AARE, is determined using Eq. (30), where $\mathrm{N}$ is the number of experimental data.

$$
\begin{aligned}
& A R E=\frac{\left|L I_{\mathrm{exp}}-L I_{\text {calc }}\right|}{L I_{\mathrm{exp}}} 100 \% \\
& A A R E=\frac{1}{N} \sum_{i=1}^{N} A R E_{i}
\end{aligned}
$$

According to Montgomery [31], the squared correlation
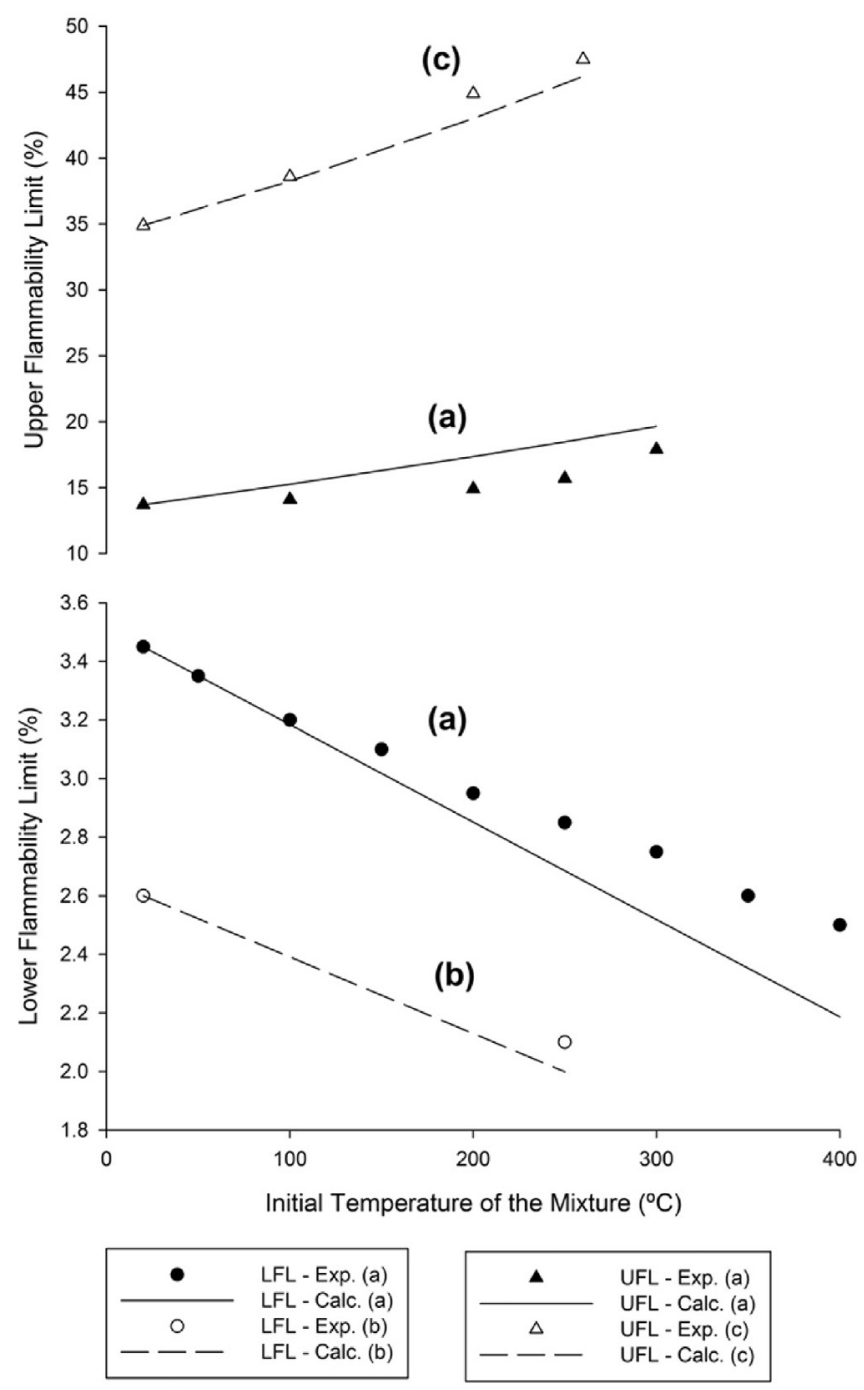

Fig. 2. Calculated and experimental flammability limits of ethylene $\left(\mathrm{C}_{2} \mathrm{H}_{4}\right)$ at different initial temperatures of the mixture and atmospheric pressure. Experimental data by: (a) White [20], (b) Craven and Foster [21] and (c) Van Den Schoor [15]. 
coefficient, $\mathrm{R}^{2}$, is calculated with Eq. (31).

$R^{2}=1-\frac{S S E}{S S T}$

where the sum of squares of the errors (SSE) and the total sum of squares (SST) are calculated using Eq. (32) and Eq. (33), respectively.

$S S E=\sum_{i=1}^{N}\left(L I_{\exp }-L I_{\text {calc }}\right)^{2}$

$S S T=\sum_{i=1}^{N}\left(L I_{\exp }\right)^{2}-\frac{\sum_{i=1}^{N} L I_{\exp }}{N}$

\subsection{Results of the method for LFL at different initial temperatures}

The results obtained by applying the methods for estimating the LFL at different initial temperatures and at atmospheric pressure are presented in this section. In total, 180 experimental points were
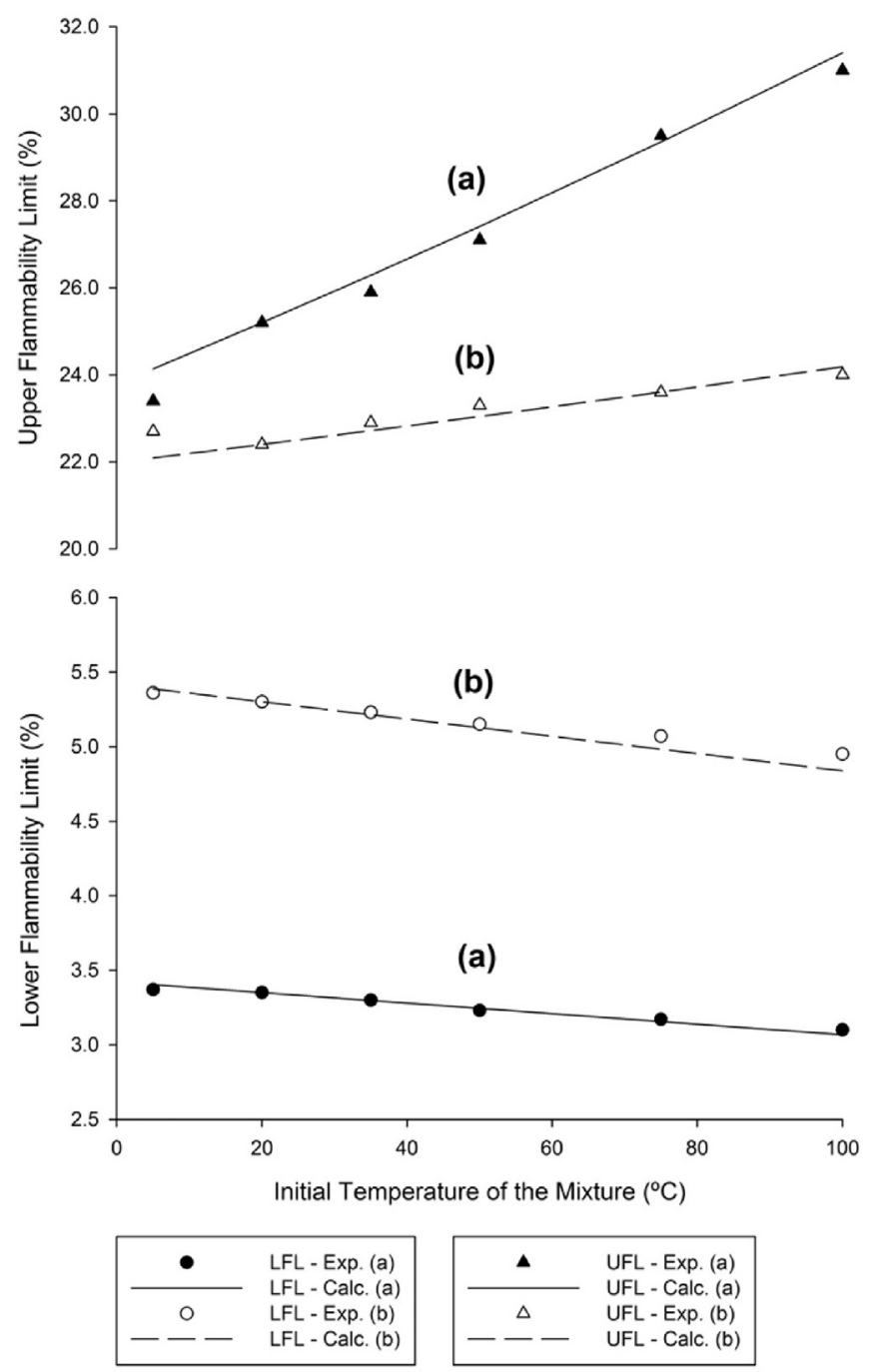

Fig. 3. Calculated and experimental flammability limits of (a) dimethyl ether $\left(\mathrm{C}_{2} \mathrm{H}_{6} \mathrm{O}\right)$ and (b) methyl formate $\left(\mathrm{C}_{2} \mathrm{H}_{4} \mathrm{O}_{2}\right)$ at different initial temperatures of the mixture and atmospheric pressure. Experimental data by Kondo et al. [17]. assessed, aside from the reference points. For the sake of comparison, Table 4 presents the results derived from the methods proposed by Britton and Frurip [6], Catoire and Naudet [3], Rowley et al. [4], and Zabetakis [2], along with the method proposed in this study.

The method developed in the present work presents better results in terms of AARE. Whereas in terms of correlation coefficient $\mathrm{R}^{2}$, the method presents better results than those by Catoire and Naudet [3] and by Rowley et al. [4]; and a slightly lower value of $\mathrm{R}^{2}$ with respect to the methods of Zabetakis [2] and Britton and Frurip [6].

Further comparison with the methods of Zabetakis [2] and Britton and Frurip [6] is presented in Table 5. Here, the data is classified into flammable gases with up to 5 carbon atoms $\left(x_{C} \leq 5\right)$, flammable gases with more than 5 carbon atoms $\left(x_{C}>5\right)$, ammonia $\left(\mathrm{NH}_{3}\right)$ and hydrogen $\left(\mathrm{H}_{2}\right)$.

When determining the LFLs of flammable gases with up to 5 carbon atoms, all the methods present similar values of $\mathrm{R}^{2}$. The method proposed by Zabetakis [2] is slightly more accurate.

The method developed in the present work presents a higher value of $\mathrm{R}^{2}(0.9851)$ when applied to determine the LFLs of
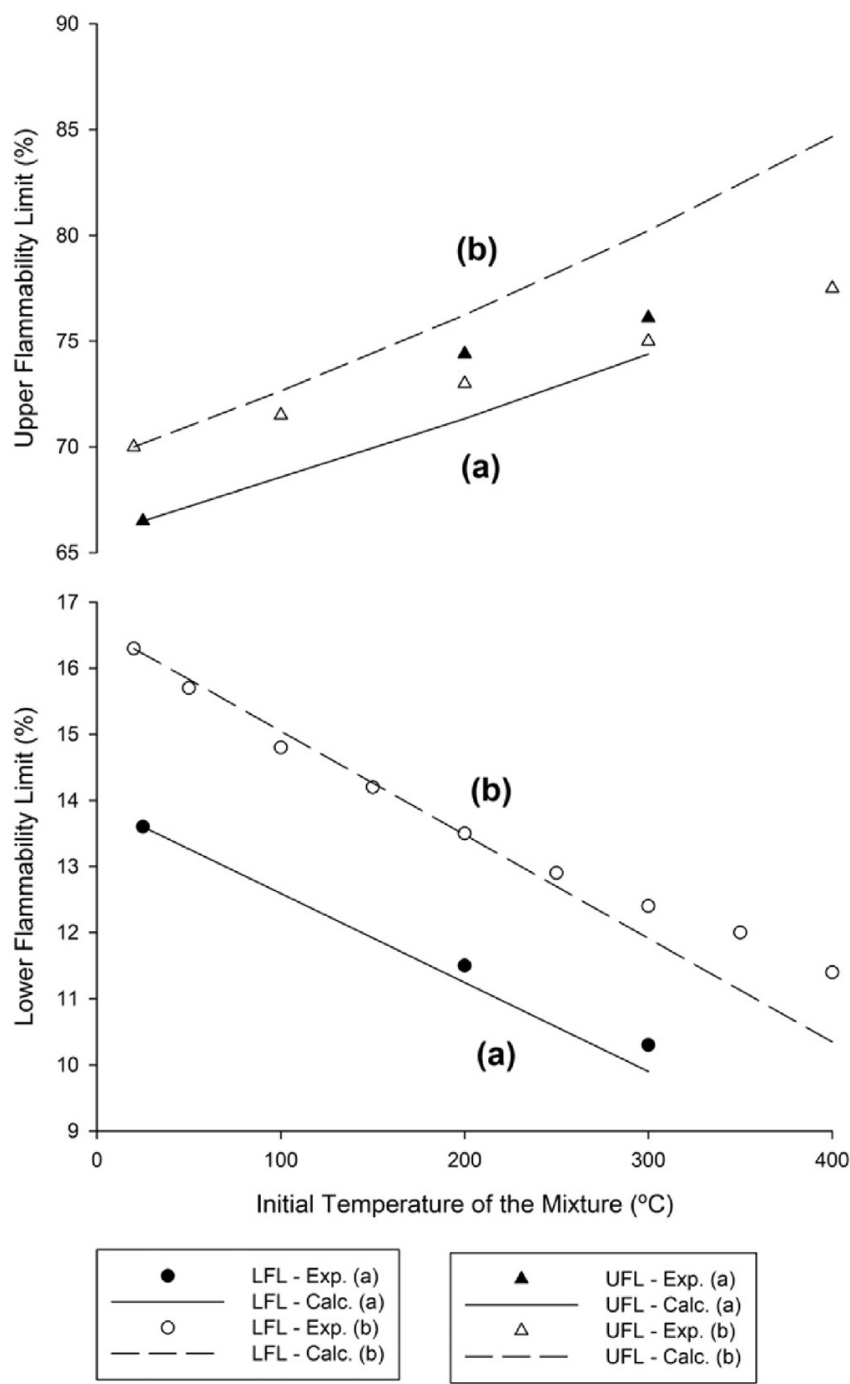

Fig. 4. Calculated and experimental flammability limits of carbon monoxide (CO) at different initial temperatures of the mixture and atmospheric pressure. Experimental data by: (a) Wierzba and Wang [18] and (b) White [20]. 
flammable gases with more than 5 carbon atoms. Therefore, the present method is more accurate for flammable gases with higher molecular weights.

In the case of ammonia, the three methods present unsatisfactory values of $\mathrm{R}^{2}$; the method of Zabetakis [2] presents the highest $R^{2}$ (0.8593). From these results, it is recommended to use the experimental values of $m_{L F L \text {.exp }}$ for ammonia, as reported in Table 2 , instead of any of the empirical methods tested here.

In the case of hydrogen, the method developed in this work presents the higher accuracy, with $\mathrm{R}^{2}$ of 0.9639 , which is considered satisfactory.

The analysis of the results reveals that the proposed method should be used for estimating the LFL at different initial temperatures of heavier flammable gases $\left(x_{C}>5\right)$. On the other hand, for lighter flammable gases $\left(x_{C} \leq 5\right)$, the method proposed by Zabetakis [2] is recommended due to its higher accuracy and simplicity of implementation.

The LFLs calculated for some flammable gases using the method proposed here are presented in Figs. 1-8; the experimental data from the different sources are also presented in the figures. A good agreement between the experimental data and the estimated values using the method proposed in the present study is observed.

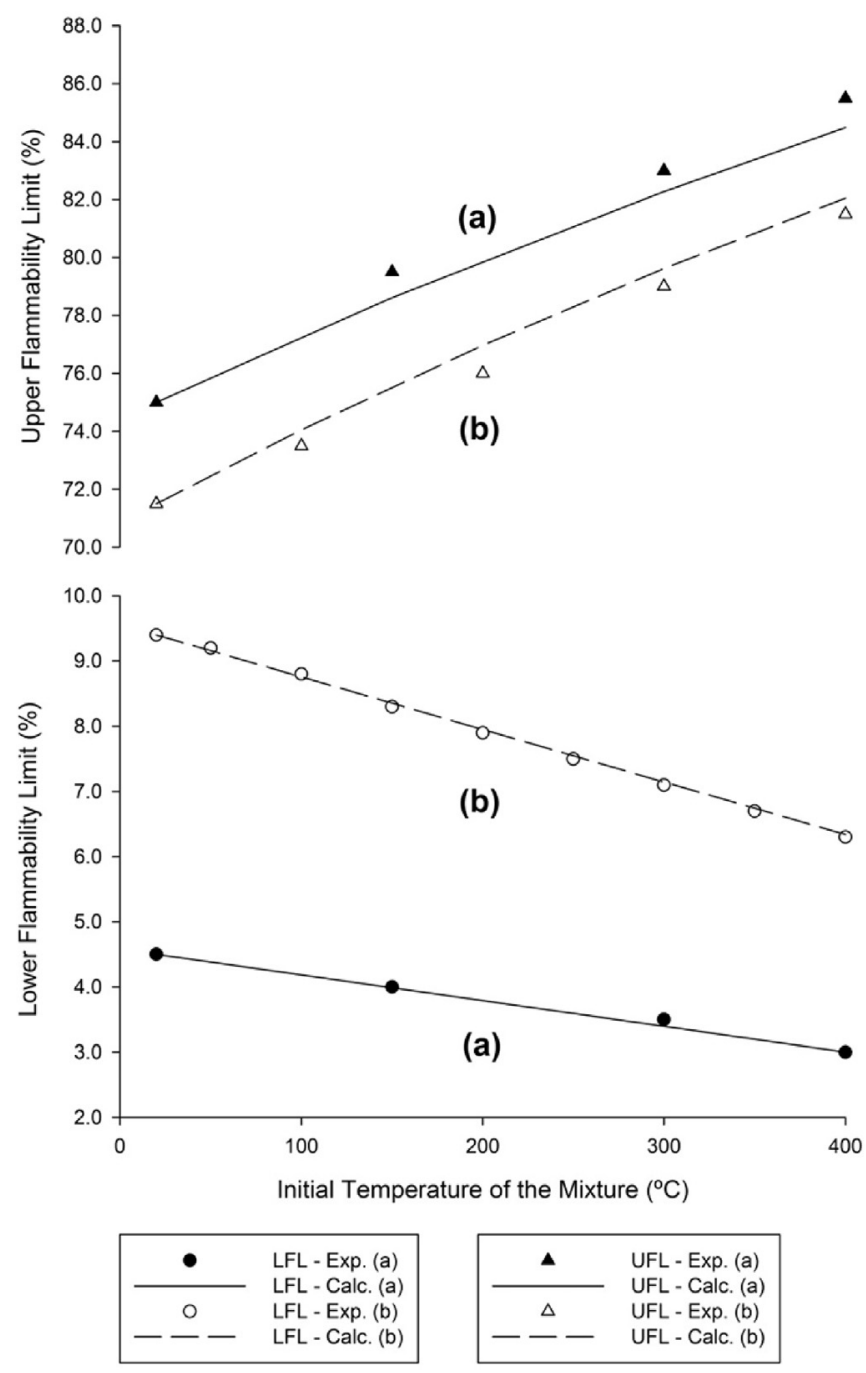

Fig. 5. Calculated and experimental flammability limits of hydrogen $\left(\mathrm{H}_{2}\right)$ at different initial temperatures of the mixture and atmospheric pressure. Experimental data by: (a) Ciccarelli et al. [24]. and White [20].

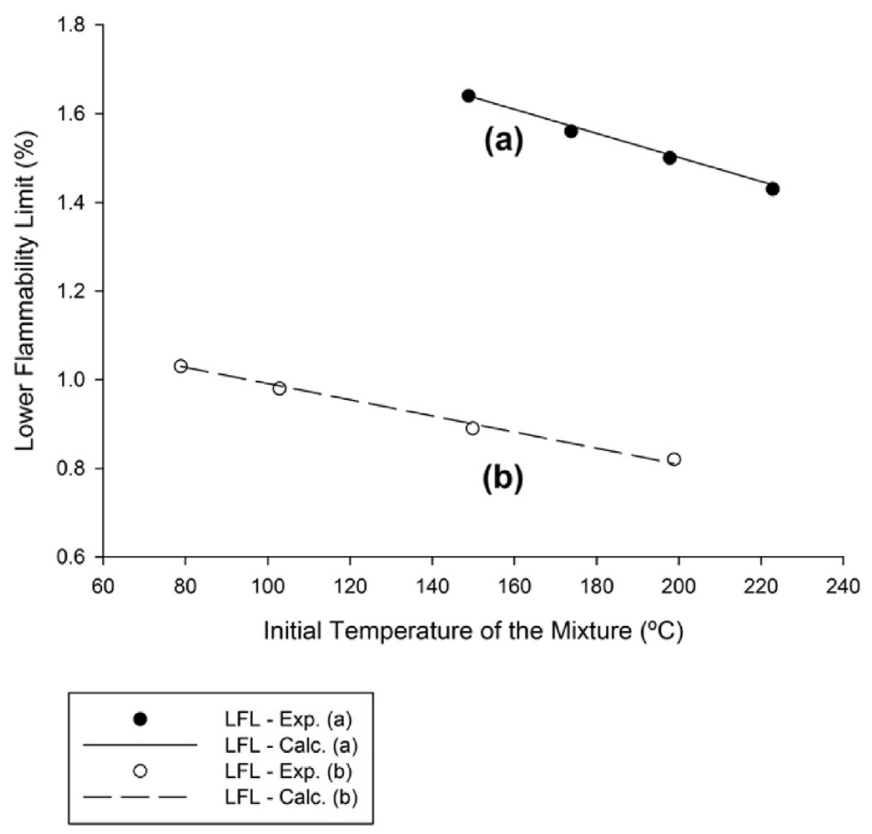

Fig. 6. Calculated and experimental flammability limits of (a) 2-methyl-1,3propanediol $\left(\mathrm{C}_{4} \mathrm{H}_{10} \mathrm{O}_{2}\right)$ and (b) hexyl formate $\left(\mathrm{C}_{7} \mathrm{H}_{14} \mathrm{O}_{2}\right)$ at different initial temperatures of the mixture and atmospheric pressure. Experimental data by Rowley et al. [28].

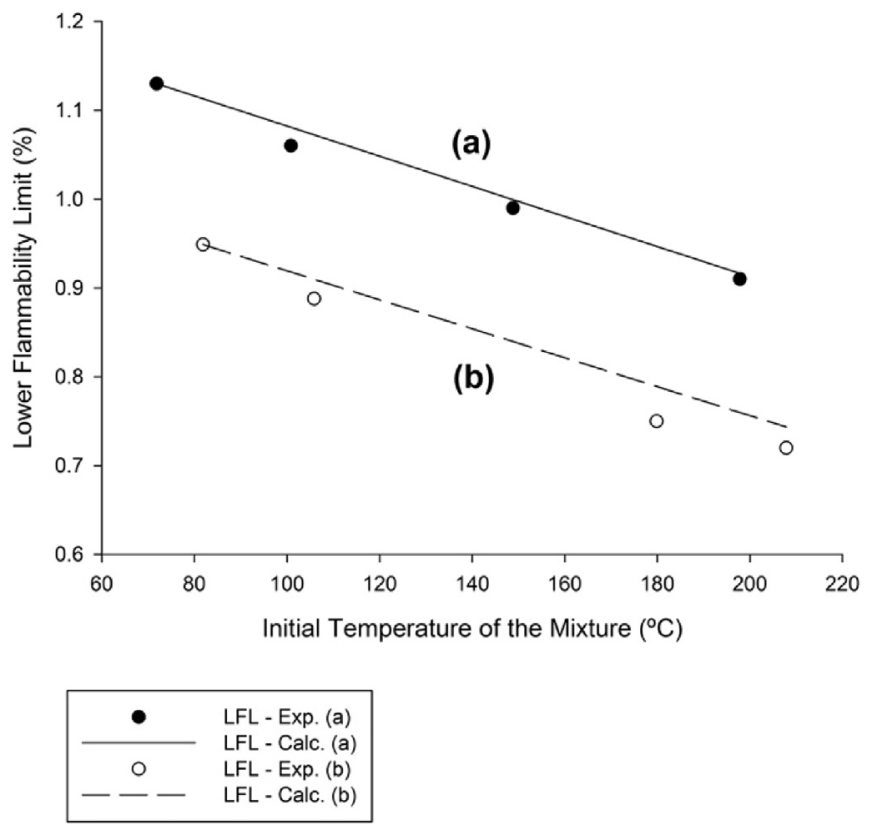

Fig. 7. Calculated and experimental flammability limits of (a) 4-methyl-2-pentanol $\left(\mathrm{C}_{6} \mathrm{H}_{14} \mathrm{O}\right)$ and (b) phenetole $\left(\mathrm{C}_{8} \mathrm{H}_{10} \mathrm{O}\right)$ at different initial temperatures of the mixture and atmospheric pressure. Experimental data by Rowley et al. [28].

The results for all the considered compounds are presented in Table S1 of the supplementary material.

\subsection{Results of the method for the UFL at different initial temperatures}

The results obtained with the methods to determine the UFLs in air at different initial temperatures and at atmospheric pressure are 

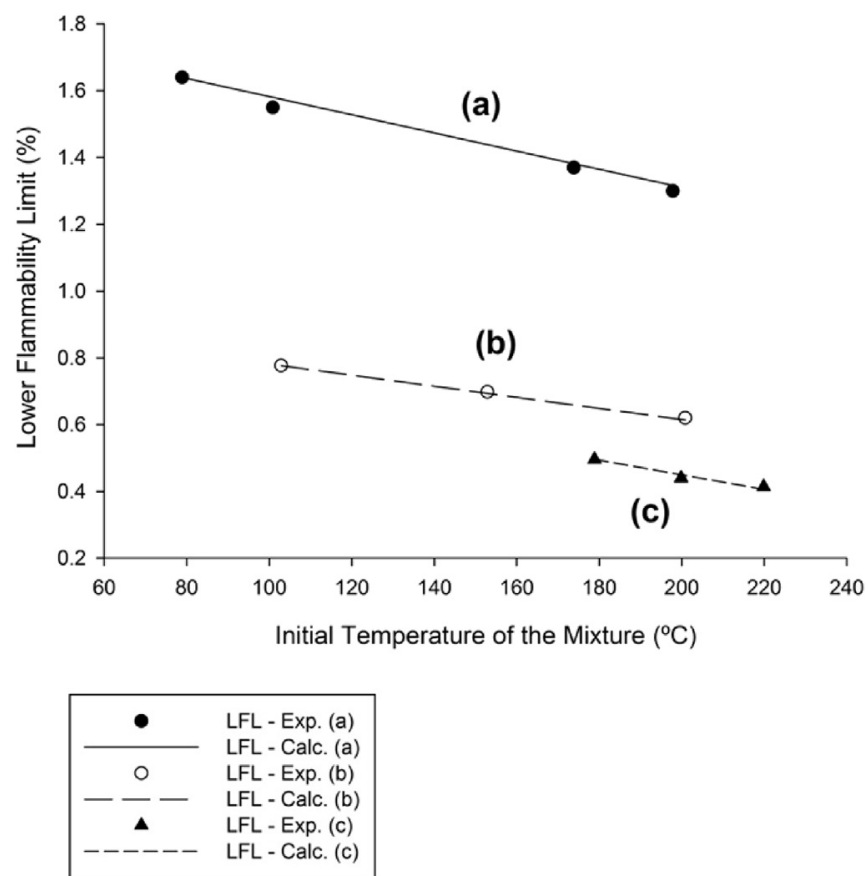

Fig. 8. Calculated and experimental flammability limits of (a) ethyl lactate $\left(\mathrm{C}_{5} \mathrm{H}_{10} \mathrm{O}_{3}\right)$, (b) octyl formate $\left(\mathrm{C}_{9} \mathrm{H}_{18} \mathrm{O}_{2}\right)$ and (c) di iso butyl phthalate $\left(\mathrm{C}_{16} \mathrm{H}_{22} \mathrm{O}_{4}\right)$ at different initial temperatures of the mixture and atmospheric pressure. Experimental data by Rowley et al. [28].

Table 6

Results and comparison of the method for determining the UFL at different initial temperatures of the mixture.

\begin{tabular}{llll}
\hline Reference & $\mathrm{N}$ & AAER (\%) & $\mathrm{R}^{2}$ \\
\hline Zabetakis [2] & 129 & 5.01 & 0.9748 \\
This work & 129 & 3.60 & 0.9957 \\
\hline
\end{tabular}

presented in Table 6 . Without considering the reference points, a total of 129 experimental points were assessed.

The method developed in the present work was compared with the method proposed by Zabetakis [2], resulting in AARE values of $3.60 \%$ and $5.01 \%$, respectively. The coefficients of determination, $R^{2}$, resulted 0.9957 for the method developed in the present work and 0.9748 for the method of Zabetakis [2]. This result implies a better accuracy of the here proposed method.

The UFLs for some flammable gases calculated with the developed method are presented in Fig. 1 through 5, along with the experimental data. The results suggest a good agreement between the experimental data and the calculated values of UFLs at different initial temperatures of mixture. The results for all the considered compounds are presented in Table S2 of the supplementary material.

\section{Conclusions}

In the present work, a method to determine the lower flammability limits (LFL) and upper flammability limits (UFL) of pure compounds in air at atmospheric pressure and at different initial temperatures was developed.

The method to determine the LFL was compared with other available methods by Zabetakis [2], Catoire and Naudet [3], Rowley et al. [4] and Britton and Frurip [6]. The method by Zabetakis [2] shows slightly better accuracy when predicting the LFL of compounds with 5 or less carbon atoms; whereas the method proposed here presents better accuracy when predicting the LFL of compounds with more than 5 carbon atoms. For the method proposed here, the average absolute relative error (AARE) is 3.25\% and the squared correlation coefficient $\left(R^{2}\right)$ results equal to 0.9928 .

With respect to method proposed here to determine the UFL, it was compared with the method presented by Zabetakis [2]. In this case, the method developed here shows better accuracy, presenting an AARE of $3.60 \%$ and a $R^{2}$ of 0.9957 .

\section{Acknowledgment}

The authors are grateful to FAPESP (Fundação de Amparo à Pesquisa do Estado de São Paulo) for support of this work through Project 2015/23351-9.

\section{Appendix A. Supplementary data}

Supplementary data related to this article can be found at http:// dx.doi.org/10.1016/j.energy.2016.12.036.

\section{References}

[1] Zabetakis MG, Lambiris S, Scott GS. Flame temperatures of limit mixtures. Symp Combust 1958;7:484-7. http://dx.doi.org/10.1016/S0082-0784(58) 80082-X.

[2] Zabetakis MG. Flammability characteristics of combustible gases and vapors. U. S Dept Inter Bur Mines 1965:1-129. http://dx.doi.org/10.2172/7328370.

[3] Catoire L, Naudet V. Estimation of temperature-dependent lower flammability limit of pure organic compounds in air at atmospheric pressure. Process Saf Prog 2005;24:130-7. http://dx.doi.org/10.1002/prs.10072.

[4] Rowley JR, Rowley RL, Wilding WV. Estimation of the lower flammability limit of organic compounds as a function of temperature. J Hazard Mater 2011;186: 551-7. http://dx.doi.org/10.1016/j.jhazmat.2010.11.039.

[5] Britton LG. Using heats of oxidation to evaluate flammability hazards. Process Saf Prog 2002;21:31-54.

[6] Britton LG, Frurip DJ. Further uses of the heat of oxidation in chemical hazard assessment. Process Saf Prog 2003;22:1-19. http://dx.doi.org/10.1002/ prs.680220102.

[7] Mendiburu AZ, De Carvalho JA, Coronado CR. Estimation of lower flammability limits of $\mathrm{C}-\mathrm{H}$ compounds in air at atmospheric pressure, evaluation of temperature dependence and diluent effect. J Hazard Mater 2015;285:409-18. http://dx.doi.org/10.1016/j.jhazmat.2014.10.058.

[8] Zlochower IA. Experimental flammability limits and associated theoretical flame temperatures as a tool for predicting the temperature dependence of these limits. J Loss Prev Process Ind 2012;25:555-60. http://dx.doi.org/ 10.1016/j.jlp.2011.12.012.

[9] Mendiburu AZ, de Carvalho JA, Coronado CR, Chumpitaz GA. Determination of lower flammability limits of $\mathrm{C}-\mathrm{H}-\mathrm{O}$ compounds in air and study of initial temperature dependence. Chem Eng Sci 2016;144:188-200. http:// dx.doi.org/10.1016/j.ces.2016.01.031.

[10] Liaw H-J, Chen K-Y. A model for predicting temperature effect on flammability limits. Fuel 2016. http://dx.doi.org/10.1016/j.fuel.2016.03.034.

[11] Mendiburu AZ, de Carvalho JA, Coronado CR. Estimation of upper flammability limits of $\mathrm{C}-\mathrm{H}$ compounds in air at standard atmospheric pressure and evaluation of temperature dependence. J Hazard Mater 2016;304:512-21. http:// dx.doi.org/10.1016/j.jhazmat.2014.10.058.

[12] Goethals M, Vanderstraeten B, Berghmans J, De Smedt G, Vliegen S, Van't Oost E. Experimental study of the flammability limits of toluene-air mixtures at elevated pressure and temperature. J Hazard Mater 1999;70:93-104.

[13] Liu X, Zhang Q. Influence of initial pressure and temperature on flammability limits of hydrogen-air. Int J Hydrogen Energy 2014;39:6774-82. http:// dx.doi.org/10.1016/j.ijhydene.2014.02.001.

[14] Vanderstraeten B, Tuerlinckx D, Berghmans J, Vliegen S, Oost EV t, Smit B. Experimental study of the pressure and temperature dependence on the upper flammability limit of methane/air mixtures. J Hazard Mater 1997;56: 237-46. http://dx.doi.org/10.1016/S0304-3894(97)00045-9.

[15] Van den Schoor F. Influence of pressure and temperature on flammability limits of combustible gases in air. Katholieke Universiteit Leuven; 2007.

[16] Hustad JE, Sonju OK. Experimental studies of lower flammability limits of gases and mixtures of gases at elevated temperatures. Combust Flame 1988;71:283-94. http://dx.doi.org/10.1016/0010-2180(88)90064-8.

[17] Kondo S, Takizawa K, Takahashi A, Tokuhashi K. On the temperature dependence of flammability limits of gases. J Hazard Mater 2011;187:585-90. http://dx.doi.org/10.1016/j.jhazmat.2011.01.037.

[18] Wierzba I, Wang Q. The flammability limits of $\mathrm{H} 2-\mathrm{CO}-\mathrm{CH} 4$ mixtures in air at elevated temperatures. Int J Hydrogen Energy 2006;31:485-9. http:// dx.doi.org/10.1016/j.ijhydene.2005.04.022. 
[19] Li Z, Gong M, Sun E, Wu J, Zhou Y. Effect of low temperature on the flammability limits of methane/nitrogen mixtures. Energy 2011;36:5521-4. http://dx.doi.org/10.1016/j.energy.2011.07.023.

[20] White AG. XCVI Limits for the propagation of flame in inflammable gas-air mixtures. Part III. The effects of temperature on the limits. J Chem Soc Trans 1925;127:672-84. http://dx.doi.org/10.1039/ct9252700672.

[21] Craven aD, Foster MG. The limits of flammability of ethylene in oxygen, air and air-nitrogen mixtures at elevated temperatures and pressures. Combust Flame 1966;10:95-100. http://dx.doi.org/10.1016/0010-2180(66)90054-X.

[22] Karim Ga, Wierzba I, Boon S. The lean flammability limits in air of methane, hydrogen and carbon monoxide at low temperatures. Cryog 1984;24:305-8. http://dx.doi.org/10.1016/0011-2275(84)90139-5 (Guildf).

[23] White AG. Limits for the propagation of flame at various temperatures in mixtures of ammonia with air and oxygen. J Chem Soc Trans 1922;121: 1688-95. http://dx.doi.org/10.1039/ct9222101688.

[24] Ciccarelli G, Jackson D, Verreault J. Flammability limits of $\mathrm{NH}_{3}-\mathrm{H}_{2}-\mathrm{N}_{2}$-air mixtures at elevated initial temperatures. Combust Flame 2006;144:53-63. http://dx.doi.org/10.1016/j.combustflame.2005.06.010.

[25] Chang YM, Hu KH, Chen JK, Shu CM. Flammability studies of benzene and methanol with different vapor mixing ratios under various initial conditions.
J Therm Anal Calorim 2006;83:107-12. http://dx.doi.org/10.1007/s10973005-7062-4.

[26] Coronado CJR, Carvalho JA, Andrade JC, Mendiburu AZ, Cortez EV, Carvalho FS et al. Flammability limits of hydrated and anhydrous ethanol at reduced pressures in aeronautical applications. J Hazard Mater 2014;280:174-84. http://dx.doi.org/10.1016/j.jhazmat.2014.07.063.

[27] Wierzba I, Harris K, Karim G. Effect of low temperature on the rich flammability limits in air of hydrogen and some fuel mixtures containing hydrogen. Int J Hydrogen Energy 1992;17:149-52. http://dx.doi.org/10.1016/03603199(92)90205-B.

[28] Rowley JR, Rowley RL, Wilding WV. Experimental determination and Reexamination of the effect of initial temperature on the lower flammability limit of pure liquids 2010:59:3063-7.

[29] National Institute of Standards and Technology. NIST Chemistry Web Book n.d. http://webbook.nist.gov/chemistry/.

[30] McBride BJ, Zehe MJ, Gordon SNASA. Glenn coefficients for calculating thermodynamic properties of individual species. NASA; 2002. p. 287.

[31] Montgomery DC. Design and analysis of experiments. fifth ed. USA: John Wiley \& Sons, Inc; 2001. 